\title{
Management of severe haemoptysis by bronchial artery embolisation in a patient with cystic fibrosis
}

\author{
A D KING, D C CUMBERLAND, S R BRENNAN \\ From the Departments of Medicine and Radiology, Northern General Hospital, Sheffield
}

\begin{abstract}
Severe haemoptysis in a patient with cystic fibrosis was successfully treated on two occasions by bronchial artery embolisation.
\end{abstract}

Small to moderate haemoptyses are often seen in patients with bronchiectasis, including those with cystic fibrosis, and it occurred in $62 \%$ of cases in one series of 316 patients with cystic fibrosis.' Severe haemoptysis is less common, and was seen in only $10 \%$ of the patients in that series; but it may be fatal. ${ }^{2}$ We have used bronchial artery embolisation for treating severe haemoptysis in a patient with cystic fibrosis.

\section{Case report}

A 16 year old girl with cystic fibrosis was admitted to hospital with severe haemoptysis in January 1988 . While under the care of the paediatricians in March 1987 a similar episode had been treated by embolisation of the right bronchial artery. When she was transferred to the adult chest clinic in June 1987 her weight was $43.5 \mathrm{~kg}$ and height $156 \mathrm{~cm}$, and she had clubbing and fair chest expansion with no added sounds on auscultation. The chest radiograph showed diffuse patchy shadowing more noticeable at the right base, and the sputum grew Pseudomonas aeruginosa. Her FEV, was 1.051 , forced vital capacity 1.41 , and peak flow rate $1651 / \mathrm{min}$.

During 1987 she had recurrent infective exacerbations but no haemoptysis until three days before admission, when she produced three cupfuls of blood during another infective episode. On examination she was pale and febrile, and had a pulse rate of 100 beats/min and a blood pressure of $110 / 65 \mathrm{~mm} \mathrm{Hg}$. There were coarse crackles throughout both lung fields, worse on the right, but no sign of cor pulmonale. Her weight was $40 \mathrm{~kg}$. The chest radiograph was unchanged and her sputum grew $P$ aeruginosa again. The haemoglobin concentration was $12.2 \mathrm{~g} / \mathrm{dl}$ and the white blood count 10.27 $\times 10^{9} / 1$; the platelet count and the clotting screen gave normal results. Treatment was started with intravenous azlocillin, flucloxacillin and tobramycin. Small haemoptyses continued over the next three days and were followed by two large haemoptyses, each of $500 \mathrm{ml}$ blood. Hypotension and tachycardia responded to transfusion with four pints $(2 \cdot 271)$ of blood. A further haemoptysis, of $300 \mathrm{ml}$, occurred the following day and she was referred once again for bronchial artery embolisation.

Address for reprint requests: Dr S R Brennan, Department of Medicine, Northern General Hospital, Sheffield S5 7AU.
The procedure took one and a half hours, during which she continued to bleed actively. A catheter was passed via the right femoral artery for selective bronchial catheterisation. Angiography showed enlarged right and left bronchial arteries, particularly the right (fig 1), with considerably increased peripheral vascularity. As is usual in bronchial haemorrhage, the bleeding site could not be seen. The right bronchial artery was embolised with small particles of lyophilised dura mater and gel foam until the flow ceased (fig 2). The haemoptysis settled during this process. As the left bronchial artery was also appreciably enlarged this too was embolised.

There were no complications and the patient was discharged five days later. During an infection a month later a little tenting of the left hemidiaphragm was seen radiographically, but there has been no recurrence of haemoptysis since the embolisation procedure nine months ago.

\section{Discussion}

Most smaller haemoptyses will settle with rest and antibiotic treatment, but larger haemoptyses need more active treatment. In localised bronchiectasis surgery may be required, but this is rarely wise in such a widespread disease as cystic fibrosis. ${ }^{3}$ Bronchial artery embolisation has been used in bronchiectasis, ${ }^{46}$ in other pulmonary haemorrhagic lesions, and in patients with widespread disease such as that seen in

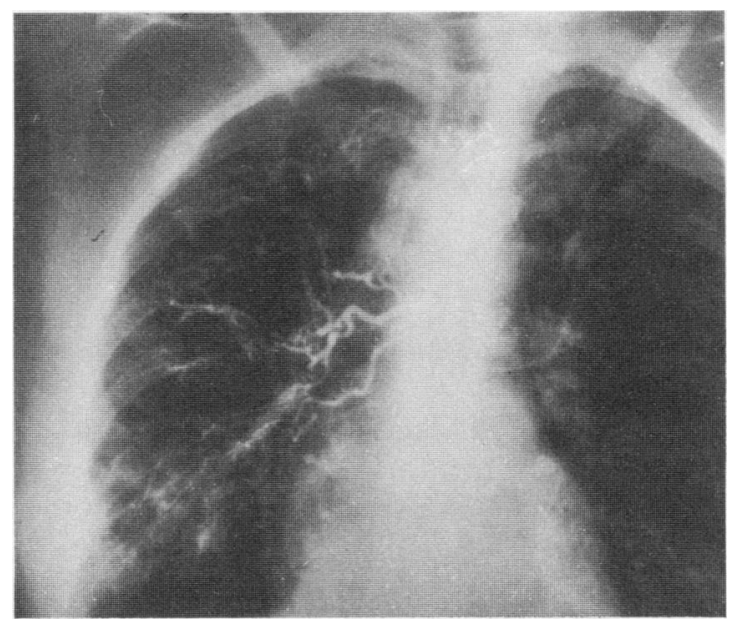

Fig 1 Radiograph showing enlarged bronchial arteries. 


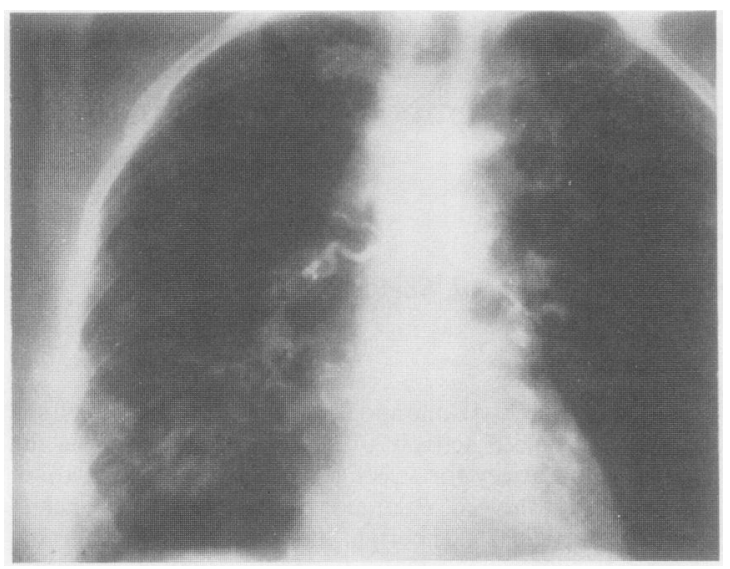

Fig 2 Radiograph showing the peripheral cut off in flow after embolisation.

cystic fibrosis. ${ }^{37}$ Difficulties may arise because of variable anatomy ${ }^{5}$ and damage to the spinal cord may occur owing to obstruction of branches of the spinal artery if fluid embolising material, such as alcohol, is injected. Particulate emboli must therefore be used, and must be small enough to occlude the distal vascular bed. When a bleeding point is not seen, occlusion of the greatly enlarged bronchial vessels may be life saving and may confer lasting relief without loss of lung tissue. ${ }^{6}$ This case shows that if bleeding does recur the procedure may be safely and effectively repeated.

Our grateful thanks are due to Dr E Priestley for the paediatric aspect of the case and Miss M Mitchell for typing the manuscript.

\section{References}

1 Penketh ARL, Wise A, Mearns MB, Hodson ME, Batten JC. Cystic fibrosis in adolescents and adults. Thorax 1987;42. 526-32.

2 Anonymous. Life threatening haemoptysis [editorial]. Lancet 1987;i:1354-6.

3 Trento A, Estner SM, Griffith BP, Hardesty RL. Massive haemoptysis in patients with CF. Three case reports. Ann Thor Surg 1985;39:254-6.

4 Uflacker R, Kaemmerer A, Neves C, Picon PD. Management of massive haemoptysis by bronchial artery embolisation. Radiology 1983;146:627-34.

5 Uflacker R, Kaemmerer A, Picon PD, et al. Bronchial artery embolisation in the management of haemoptysis. Radiology 1985;157:637-44.

6 Rabkin JE, Astafjev VI, Gothman LN, Grigorjev YG. Transcatheter embolisation in the management of pulmonary haemorrhage. Radiology 1987;163:361-5.

7 Fellows KE, Stigol L, Shuster S, Khaw KT, Shwachman H. Selective bronchial arteriography in patients with CF and massive haemoptysis. Radiology 1975;114:551-6. 